\title{
Role of endoscopic ultrasound in pediatric gastrointestinal diseases
}

\author{
Rajiv Ranjan Singh, Narendra Singh Choudhary, Rajesh Puri \\ Institute of Digestive and Hepatobiliary Sciences, Medanta - The Medicity, Gurgaon, Haryana, India
}

\begin{abstract}
Endoscopic ultrasound (EUS) is a well-established diagnostic and therapeutic modality for adults. It is extremely helpful for a broad range of diagnostic indications including upper gastrointestinal (GI) malignancies, submucosal lesions, pancreatic lesions (masses, cystic lesions), chronic pancreatitis, etiological workup of recurrent acute pancreatitis, common bile duct evaluation (calculi versus tumor), gallbladder lesions/microliths, and rectal malignancy; well-established therapeutic roles include fine-needle aspiration of lesions/lymph nodes, pancreatic fluid collection drainage, pancreatic duct drainage, biliary drainage, gallbladder drainage, pelvic abscess drainage, celiac plexus block, or neurolysis. Some recent studies have reported the use of EUS in the pediatric population. EUS is safe and easy to perform in the pediatric population also. However, there is paucity of data on use of EUS in pediatric population. In contrast with its regular therapeutic use in adults, EUS is not commonly performed in children for therapeutic reasons and most of the data are available on diagnostic use only. All of studies have shown that EUS is safe and a useful modality with a positive impact on management in majority of study population. EUS is very useful in pediatric population for the evaluation of upper GI tract submucosal lesions or rectal masses, pancreaticobiliary disorders, characterization of esophageal strictures, and for evaluation of enteric duplication cysts. The advent of miniprobe that can be passed through conventional endoscopes has increased the applicability of EUS in infants and children. Although there are limited data regarding use of EUS in pediatric population, it appears to be a very promising diagnostic and therapeutic tool.

Key words Endoscopic ultrasound, gastrointestinal diseases, pediatric patients
\end{abstract}

\section{Introduction}

Endoscopic ultrasound (EUS) is an evolving diagnostic and therapeutic modality that allows an accurate imaging of gastrointestinal (GI) tract and its periluminal structures. Since its advent in 1980, there has been progressive expansion of its domain owing to improvement in equipment

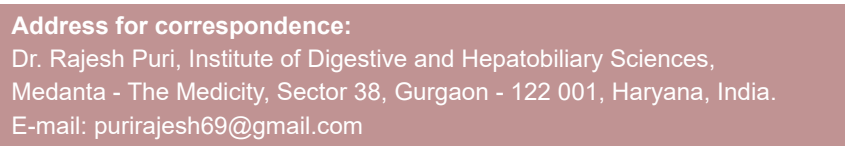

\begin{tabular}{|l|c|}
\hline \multicolumn{2}{|c|}{ Access this article online } \\
\hline \multirow{2}{*}{$\begin{array}{l}\text { Website: } \\
\text { www.jdeonline.in }\end{array}$} & Quick Response Code \\
\hline DOI: & \\
10.4103/0976-5042.193738 & \\
&
\end{tabular}

design, endoscopic techniques, and development of better accessories. ${ }^{[1]}$

The role of EUS is well-established in adult population. However, it has not been adequately evaluated in pediatric GI and pancreaticobiliary disorders. It may be due to relatively low incidence of pancreaticobiliary and luminal GI cancers, absence of dedicated pediatric echoendoscopes, need for deep sedation or general anesthesia, and challenges of esophageal and duodenal intubation in small children; feasibility of

This is an open access article distributed under the terms of the Creative Commons Attribution-NonCommercial-ShareAlike 3.0 License, which allows others to remix, tweak, and build upon the work non-commercially, as long as the author is credited and the new creations are licensed under the identical terms.

For reprints contact: reprints@medknow.com

How to cite this article: Singh RR, Choudhary NS, Puri R. Role of endoscopic ultrasound in pediatric gastrointestinal diseases. J Dig Endosc 2016;7:104-9. 
endoscopy in children is shown in Table $1 .^{[2]}$ Some studies have reported EUS being used for both diagnostic and therapeutic purposes in children, with excellent safety and significant impact on patient management. ${ }^{[3,4]}$

\section{Indications}

In children, EUS is most commonly performed for evaluation of pancreatitis (recurrent acute, chronic), suspected choledocholithiasis, benign/malignant lymphadenopathy, benign submucosal lesions, for example, ectopic pancreas, esophageal and duodenal duplication cysts, and pancreatic solid/cystic lesions. The list of indications for EUS in pediatric age group is progressively expanding. It can be divided into pancreaticobiliary and intestinal indications [Table 2]. Impact of EUS in pediatric patients in various studies is shown in Table 3. ${ }^{[3-9]}$ Impact on patient management ranges from $35.5 \%$ to $98 \%$ in various studies.

\section{Pancreaticobiliary Disorders}

EUS has been most extensively studied for pancreaticobiliary indications, in both adults and children. It is the most accurate diagnostic modality for choledocholithiasis, biliary stricture, pancreaticobiliary solid, and cystic mass lesions. ${ }^{[10,11]}$ EUS-guided fine-needle aspiration (FNA) can be used to obtain tissue/fluid for cytopathological and histopathological examination, thus allowing a definitive diagnosis. ${ }^{[12]}$ Representative images of pediatric EUS are shown in Figure 1. EUS also allows a better delineation of pancreatic morphology and its various structural changes due to proximity of probe to pancreatic parenchyma. ${ }^{[13]}$

A recent retrospective study reported the role of EUS performed for pancreaticobiliary indications in children. ${ }^{[6]}$ The authors performed 52 diagnostic and therapeutic EUS procedures in 48 children, spanning over a period of 14 years and they demonstrated that EUS was technically feasible and safe procedure in children. The study showed a positive impact of EUS in 51 of 52 procedures. A recently published retrospective study from India reemphasized the safety and efficacy of EUS in children; ${ }^{[9]} 123$ diagnostic and 2 therapeutic EUS procedures were performed in 121 children. The most common indication was pancreaticobiliary (118 procedures in 114 children) followed by mediastinum $(n=5)$ and stomach $(n=2)$. EUS diagnosed chronic pancreatitis $(n=21)$, pseudocysts $(n=3)$, pancreatic necrosis $(n=1)$, pancreatic masses $(n=4$ including 2 insulinomas), choledocholithiasis $(n=2)$, choledochal cysts $(n=2)$, portal biliopathy $(n=1)$, esophageal leiomyoma $(n=1)$, gastric varix $(n=1)$, gastric neuroendocrine tumor $(n=1)$, GI stromal tumor in stomach $(n=1)$, and splenic artery pseudoaneurysm $(n=1)$. EUS-guided FNA cytology was positive in four of seven patients (two had tuberculosis, one pancreatic solid pseudopapillary tumor, and one gastric neuroendocrine tumor). A positive clinical impact was documented in $43(35.5 \%)$ patients with minor adverse events in three patients. ${ }^{[9]}$

Single session procedures combining EUS with endoscopic retrograde cholangiopancreatography (ERCP) in children with suspected biliary obstruction has been used for both diagnosis and relief of obstruction. It allows both procedures to be performed in same sedation. In a recent study, ${ }^{[6]} 9$ combined EUS-ERCP were safely performed in 7 children. It also avoided unnecessary ERCP in 13 patients with suspected biliary obstruction due to choledocholithiasis. EUS has much better sensitivity for biliary microlithiasis compared to conventional

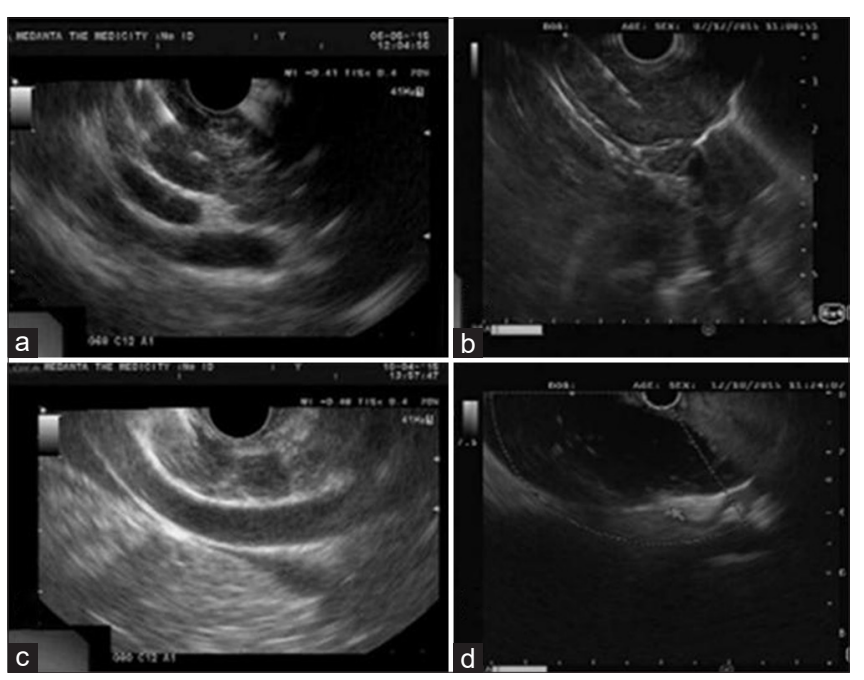

Figure 1: (a) Linear endoscopic ultrasound image of mediastinal lymph node, fine-needle aspiration suggestive of chronic granulomatous necrotizing lymphadenitis due to mycobacterial organisms (b) linear endoscopic ultrasound image of posterior mediastinal mass in a 11-year-old girl, fine-needle aspiration suggestive of mesenchymal neoplasm (c) linear endoscopic ultrasound image of abdominal lymph node, fine-needle aspiration suggestive of reactive lymphadenopathy (d) linear endoscopic ultrasound image showing gall bladder microliths in a case of recurrent idiopathic pancreatitis

\begin{tabular}{llll}
\hline \multicolumn{2}{l}{ Table 1: Feasibility of EUS in children (adapted from American Society for Gastrointestinal Endoscopy, 2012) } \\
\hline Weight $\mathbf{( k g )}$ & EGD & ERCP & Colon \\
\hline$<2.5$ & $<6-\mathrm{mm}$ gastroscope & $7.5-\mathrm{mm}$ duodenoscope & $<6$-mm gastroscope \\
$2.5-10$ & $<6-\mathrm{mm}$ gastroscope preferred, & $7.5-\mathrm{mm}$ duodenoscope & $<6$-mm gastroscope or standard adult \\
& $\begin{array}{l}\text { or standard adult gastroscope } \\
\text { Standard adult gastroscope }\end{array}$ & Standard therapeutic & gastroscope \\
& & duodenoscope & 11- to 11.6-mm pediatric colonoscope \\
& & or adult colonoscope
\end{tabular}

$\mathrm{EGD}=$ Esophagogastroduodenoscopy, ERCP=Endoscopic Retrograde Cholangio-Pancreatography 
imaging techniques including computed tomography (CT), magnetic resonance cholangiopancreatography, and hepatobiliary scan..$^{[14]}$

Pancreatic cystic lesions are incidentally detected in $2.6 \%$ of abdominal multidetector CT examinations and $20 \%$ of magnetic resonance imaging (MRI) studies ${ }^{[15-17]}$ and they can be benign, premalignant, or frankly malignant. EUS allows characterization of cystic lesions as well as their drainage [Table 4]. ${ }^{[18-20]}$ EUS-guided cyst fluid aspiration and analysis (cytopathology, fluid carcinoembryonic antigen (CEA), mucin, and amylase levels) help in diagnosis and deciding on optimal management option. ${ }^{[21-25]} \mathrm{A}$ CEA

\begin{tabular}{ll}
\hline Table 2: Indications of EUS in pediatric patients \\
\hline Pancreaticobiliary indications & Intestinal indications \\
\hline Benign & Benign \\
Suspected choledocholithiasis & Esophageal strictures \\
Malignant & Known/suspected \\
Cholangiocarcinoma & achalasia \\
Malignant lymphadenopathy & Esophageal varices \\
Pancreatic adenocarcinoma & Esophageal duplications \\
Pancreatic ductal adenocarcinoma & Pyloric stenosis \\
Intraductal papillary mucinous & Congenital duodenal \\
neoplasm Mucinous cystic neoplasm & duplications \\
Endocrine neoplasm & Submucosal lesions \\
Serous cystadenoma & Leiomyoma \\
& Lipoma \\
& Ectopic pancreas \\
& Hypertrophic gastric \\
& folds \\
& Rectal heterotopic \\
& gastric mucosa \\
& Malignant \\
& Malignant \\
& lymphadenopathy \\
& GIST \\
& Leiomyosarcoma \\
& Gastric cancer \\
& Lymphoma \\
\hline
\end{tabular}

concentration of $192 \mathrm{ng} / \mathrm{mL}$ provides $84 \%$ specificity in differentiation of mucinous from nonmucinous lesions. ${ }^{\text {[25-29] }}$ Mucinous lesions detected with mucicarmine staining, cysts with high CEA and low-amylase levels are more likely to carry malignant potential.

EUS can be used for evaluation of pancreaticobiliary malignancies detected by conventional imaging techniques. It allows staging and sampling of lesions and can guide management decisions. ${ }^{[30,31]}$ EUS-guided FNA has high diagnostic accuracy for solid pancreatic lesions which are often difficult to diagnose by other biopsy methods including CT-guide biopsy. EUS FNA provides a sensitivity, specificity, positive predictive value, negative predictive value, and accuracy of $84.3 \%, 97 \%, 99 \%, 64 \%$, and $84 \%$, respectively, for solid pancreatic masses which could not be diagnosed by other methods. ${ }^{[32]}$

The role of EUS in the evaluation and management of complications of portal hypertension, especially gastroesophageal varices are evolving. It can help assess the risk of variceal development, bleeding, efficacy of eradication therapy, and rebleeding risk. ${ }^{[3-35]}$ EUS has higher sensitivity for detection of gastroesophageal varices compared to esophagogastroduodenoscopy. ${ }^{[36]}$ EUS can predict the risk of variceal bleeding by assessing its cross-sectional area. ${ }^{[3]}$ The diameter of left gastric vein corresponds with variceal size. ${ }^{[37]}$ A rapid hepatofugal flow velocity $\geq 12 \mathrm{~cm} / \mathrm{s}$ in the left gastric vein detected by color Doppler EUS examination suggests a high risk of an early recurrence of esophageal varices treated with either esophageal band ligation or sclerotherapy. ${ }^{[38]}$ The recently described EUS-guided cyanoacrylate injection with or without coil embolization of varices is highly effective, requires fewer endoscopic sessions, and results in fewer adverse events. ${ }^{[39-41]}$ Although it has been described in adults, it can be safely applied to children as well. However, it needs further studies involving pediatric patients.

\begin{tabular}{|c|c|c|c|}
\hline Author (year) & Age, mean (range) & Patients, total/PB & Impact \\
\hline Varadarajulu, Gastrointest Endosc 2005 ${ }^{[3]}$ & $13(5-17)$ & 15/15, precluded ERCP in 9 & $93 \%$ \\
\hline Cohen, JPGN 2008 ${ }^{[4]}$ & $12(1.5-18)$ & $32 / 19$, FNA in 7 & $44 \%$ \\
\hline Bjerring, JPGN 2008 ${ }^{[5]}$ & $12(0.5-15)$ & $18 / 13$ & $78 \%$ \\
\hline Attila, Gastro-intest Endosc 2009[6] & $13.5(3-17)$ & 38/25, FNA 9/12 accuracy & NA \\
\hline Al-Rashdan, JPGN 2010[7] & $16(4-18)$ & $\begin{array}{l}56 / 46,4 \text { celiac block, } 1 \text { EUS guided } \\
\text { pancreatogram }\end{array}$ & $86 \%$ \\
\hline Scheers I, JPGN 2015[8] & $12(2-17)$ & $51 / 52$ & $98 \%$ \\
\hline Mahajan, IJG 2016 ${ }^{[9]}$ & $15.2(3-18)$ & 121/114, FNA 4/7 accuracy & $35.5 \%$ \\
\hline
\end{tabular}

PB=Pancreaticobiliary, FNA=Fine Needle Aspiration

Table 4: EUS guided pancreatic fluid collection drainage

\begin{tabular}{lclc}
\hline Author (year) & \multicolumn{1}{c}{ Age } & Patients & Impact \\
\hline Ramesh, JPGN 2013 & 8.4+2.1 years & 7 PFC drain & Success 100\%, 2 reintervention \\
De Angelis, World J Gastrointest Endosc 2013 ${ }^{[19]}$ & 7,10 and 11 years & Miniprobe drainage in 3 & $100 \%$ \\
Jazrawi Dig Dis Sci 2011[20] & $11.8(4-17)$ years & 10 PFC, 8 drainage, 2 aspiration & $100 \%$ \\
\hline
\end{tabular}




\section{Intestinal Indications}

Congenital esophageal stenosis (CES) is an extremely rare malformation consisting of 3 types: fibromuscular thickening (54\%), tracheobronchial remnants (TBR, 30\%), and membranous web (16\%). ${ }^{[42-44]}$ Standard diagnostic criteria and treatment have not yet been established. Endoscopic dilatation and surgery are treatment options where surgery is reserved for ineffective dilatation. However, the efficacy and risk of these procedures are controversial. Dilatation for TBR type of CES has low-success rate and high rate of perforation. EUS helps differentiate different types of CES with TBR showing multiple echogenic regions in the muscle layer that represent aberrant cartilaginous remnants. EUS findings of TBR correlate well with surgical pathology. ${ }^{[45]}$ Overall success rate of dilatation and rate of perforation for CES with or without case selection using EUS are $90 \%$ and $29 \%$ and $7 \%$ and $24 \%$, respectively. ${ }^{[46]}$ Hence, EUS-guided repetitive dilatation with gradual step up can be a safe approach to minimize the risk of perforation.

EUS can detect various congenital anomalies of GI tract and guide their management. EUS is the modality of choice to evaluate and diagnose duplication cysts as it can distinguish between solid and cystic lesions. ${ }^{[4]]}$ EUS can also delineate cyst location relative to surrounding tissues effectively guiding surgical or endoscopic therapies. ${ }^{[48,49]}$ Duodenal duplication cysts are adherent to the duodenum, are noncommunicating, and may occasionally include the distal part of the pancreaticobiliary duct or a vessel within its common wall. EUS guided minimally invasive endoscopic therapy or intracavitary surgery allowing resection of the common wall is currently the preferred treatment in children with biliary involvement. ${ }^{[50]}$ Ectopic pancreatic rests, often seen in stomach, duodenum or jejunum can sometimes be mistaken with a tumor owing to its endoscopic appearance or associated symptoms. EUS can identify these benign embryologic structures as anechoic, isoechoic, or hypoechoic structures contained within the submucosa. ${ }^{[51]}$ EUS assessment of depth of submucosal infiltration by heterotopic gastric mucosa in rectum can help in deciding the appropriate treatment modality. ${ }^{[52]}$

High-resolution EUS demonstrates increased thickness of esophageal wall as well as its individual wall layers including the combined mucosa and submucosa, and muscularis propria in children with eosinophilic esophagitis compared with healthy controls. Treatment with steroids results in decrease in wall thickness. ${ }^{[53,54]}$ EUS can help define the etiology and treatment strategy in children with esophageal stenosis. ${ }^{[5]}$ Disruption of submucosal and muscular layers seen on EUS suggests gastroesophageal reflux resulting in esophageal stenosis. It can delineate the depth of injury in patients with caustic injury, thereby determining the need for endoscopic/ surgical therapy. EUS can determine the extent of disease and efficacy of endoscopic or surgical therapy in patients with achalasia, a rare disorder in children. ${ }^{[56]}$
EUS can help differentiate patients with inflammatory bowel disease into active ulcerative colitis (UC) and Crohn's disease (CD) and quantify the level of colonic inflammation. ${ }^{[57]}$ Estimation of mucosal-submucosal and total wall thickness with locoregional lymph node assessment by EUS has $92 \%$ sensitivity in discriminating UC and CD. EUS can predict remission and relapses in patients with inflammatory bowel disease based on changes in wall thickness. ${ }^{[58-60]}$ EUS has been demonstrated to be superior to fistulography, CT, and equal to or superior to MRI in evaluation of perirectal and perianal complications of CD. ${ }^{[59]}$ It better delineates the length and extent of ileocolonic strictures in $\mathrm{CD}$, thus allowing optimal medical/surgical treatment in these patients.

\section{Future Perspectives}

With progressively increasing number of EUS indications in children, it is likely to gain more acceptances for pediatric population. EUS miniprobes or endoscopic bronchial probes (provides option of FNA also) can be used in smaller children. More data are required on therapeutic applications of EUS in children.

\section{Financial support and sponsorship \\ Nil.}

\section{Conflicts of interest}

There are no conflicts of interest.

\section{References}

1. DiMagno EP, Buxton JL, Regan PT, Hattery RR, Wilson DA, Suarez JR, et al. Ultrasonic endoscope. Lancet 1980;1:629-31.

2. ASGE Technology Committee, Barth BA, Banerjee S, Bhat YM, Desilets DJ, Gottlieb KT, et al. Equipment for pediatric endoscopy. Gastrointest Endosc 2012;76:8-17.

3. Varadarajulu S, Wilcox CM, Eloubeidi MA. Impact of EUS in the evaluation of pancreaticobiliary disorders in children. Gastrointest Endosc 2005;62:239-44.

4. Cohen S, Kalinin M, Yaron A, Givony S, Reif S, Santo E. Endoscopic ultrasonography in pediatric patients with gastrointestinal disorders. J Pediatr Gastroenterol Nutr 2008;46:551-4.

5. Bjerring OS, Durup J, Qvist N, Mortensen MB. Impact of upper gastrointestinal endoscopic ultrasound in children. J Pediatr Gastroenterol Nutr 2008;47:110-3.

6. Attila T, Adler DG, Hilden K, Faigel DO. EUS in pediatric patients. Gastrointest Endosc 2009;70:892-8.

7. Al-Rashdan A, LeBlanc J, Sherman S, McHenry L, DeWitt J, Al-Haddad M. Role of endoscopic ultrasound for evaluating gastrointestinal tract disorders in pediatrics: A tertiary care center experience. J Pediatr Gastroenterol Nutr 2010;51:718-22.

8. Scheers I, Ergun M, Aouattah T, Piessevaux H, Borbath I, Stephenne X, et al. Diagnostic and therapeutic roles of endoscopic ultrasound in pediatric pancreaticobiliary disorders. J Pediatr Gastroenterol Nutr 2015;61:238-47.

9. Mahajan R, Simon EG, Chacko A, Reddy DV, Kalyan PR, Joseph AJ, et al. Endoscopic ultrasonography in pediatric patients - Experience from a tertiary care center in India. Indian J Gastroenterol 2016;35:14-9.

10. Kim E, Telford JJ. Endoscopic ultrasound advances, part 1: Diagnosis. Can J Gastroenterol 2009;23:594-601. 
11. ASGE Standards of Practice Committee, Gan SI, Rajan E, Adler DG, Baron TH, Anderson MA, et al. Role of EUS. Gastrointest Endosc 2007;66:425-34.

12. Erickson RA. EUS-guided FNA. Gastrointest Endosc 2004;60:267-79.

13. Kitano M, Sakamoto H, Matsui U, Ito Y, Maekawa K, von Schrenck T, et al. A novel perfusion imaging technique of the pancreas: Contrast-enhanced harmonic EUS (with video). Gastrointest Endosc 2008;67:141-50.

14. Neff LP, Mishra G, Fortunato JE, Laudadio J, Petty JK. Microlithiasis, endoscopic ultrasound, and children: Not just little gallstones in little adults. J Pediatr Surg 2011;46:462-6.

15. Laffan TA, Horton KM, Klein AP, Berlanstein B, Siegelman SS, Kawamoto S, et al. Prevalence of unsuspected pancreatic cysts on MDCT. AJR Am J Roentgenol 2008;191:802-7.

16. Lee HJ, Kim MJ, Choi JY, Hong HS, Kim KA. Relative accuracy of CT and MRI in the differentiation of benign from malignant pancreatic cystic lesions. Clin Radiol 2011;66:315-21.

17. Zhang XM, Mitchell DG, Dohke M, Holland GA, Parker L. Pancreatic cysts: Depiction on single-shot fast spin-echo MR images. Radiology 2002;223:547-53.

18. Ramesh J, Bang JY, Trevino J, Varadarajulu S. Endoscopic ultrasound-guided drainage of pancreatic fluid collections in children. J Pediatr Gastroenterol Nutr 2013;56:30-5.

19. De Angelis P, Romeo E, Rea F, Torroni F, Caldaro T, Federici di Abriola G, et al. Miniprobe EUS in management of pancreatic pseudocyst. World J Gastrointest Endosc 2013;5:255-60.

20. Jazrawi SF, Barth BA, Sreenarasimhaiah J. Efficacy of endoscopic ultrasound-guided drainage of pancreatic pseudocysts in a pediatric population. Dig Dis Sci 2011;56:902-8.

21. Sakorafas GH, Smyrniotis V, Reid-Lombardo KM, Sarr MG. Primary pancreatic cystic neoplasms revisited. Part III. Intraductal papillary mucinous neoplasms. Surg Oncol 2011;20:e109-18.

22. Sakorafas GH, Smyrniotis V, Reid-Lombardo KM, Sarr MG. Primary pancreatic cystic neoplasms revisited: Part II. Mucinous cystic neoplasms. Surg Oncol 2011;20:e93-101.

23. Sakorafas GH, Smyrniotis V, Reid-Lombardo KM, Sarr MG. Primary pancreatic cystic neoplasms revisited. Part I: Serous cystic neoplasms. Surg Oncol 2011;20:e84-92.

24. Sakorafas GH, Smyrniotis V, Reid-Lombardo KM, Sarr MG. Primary pancreatic cystic neoplasms of the pancreas revisited. Part IV: Rare cystic neoplasms. Surg Oncol 2012;21:153-63.

25. Brugge WR, Lewandrowski K, Lee-Lewandrowski E, Centeno BA, Szydlo T, Regan S, et al. Diagnosis of pancreatic cystic neoplasms: A report of the cooperative pancreatic cyst study. Gastroenterology 2004;126:1330-6.

26. Michaels PJ, Brachtel EF, Bounds BC, Brugge WR, Pitman MB. Intraductal papillary mucinous neoplasm of the pancreas: Cytologic features predict histologic grade. Cancer 2006;108:163-73.

27. Hutchins GF, Draganov PV. Cystic neoplasms of the pancreas: A diagnostic challenge. World J Gastroenterol 2009;15:48-54.

28. Park WG, Mascarenhas R, Palaez-Luna M, Smyrk TC, O’Kane D, Clain JE, et al. Diagnostic performance of cyst fluid carcinoembryonic antigen and amylase in histologically confirmed pancreatic cysts. Pancreas 2011;40:42-5.

29. Pitman MB, Michaels PJ, Deshpande V, Brugge WR, Bounds BC. Cytological and cyst fluid analysis of small $(<$ or $=3 \mathrm{~cm})$ branch duct intraductal papillary mucinous neoplasms adds value to patient management decisions. Pancreatology 2008;8:277-84.

30. Afify AM, al-Khafaji BM, Kim B, Scheiman JM. Endoscopic ultrasound-guided fine needle aspiration of the pancreas. Diagnostic utility and accuracy. Acta Cytol 2003;47:341-8.

31. Harewood GC, Wiersema MJ. Endosonography-guided fine needle aspiration biopsy in the evaluation of pancreatic masses. Am J Gastroenterol 2002;97:1386-91.

32. Eloubeidi MA, Chen VK, Eltoum IA, Jhala D, Chhieng DC, Jhala N, et al. Endoscopic ultrasound-guided fine needle aspiration biopsy of patients with suspected pancreatic cancer: Diagnostic accuracy and acute and 30-day complications. Am J Gastroenterol 2003;98:2663-8.
33. Konishi Y, Nakamura T, Kida H, Seno H, Okazaki K, Chiba T. Catheter US probe EUS evaluation of gastric cardia and perigastric vascular structures to predict esophageal variceal recurrence. Gastrointest Endosc 2002;55:197-203.

34. Lahoti S, Catalano MF, Alcocer E, Hogan WJ, Geenen JE. Obliteration of esophageal varices using EUS-guided sclerotherapy with color Doppler. Gastrointest Endosc 2000;51:331-3.

35. Masalaite L, Valantinas J, Stanaitis J. Endoscopic ultrasound findings predict the recurrence of esophageal varices after endoscopic band ligation: A prospective cohort study. Scand J Gastroenterol 2015;50:1322-30.

36. Choudhuri G, Dhiman RK, Agarwal DK. Endosonographic evaluation of the venous anatomy around the gastro-esophageal junction in patients with portal hypertension. Hepatogastroenterology 1996;43:1250-5.

37. Hino S, Kakutani H, Ikeda K, Uchiyama Y, Sumiyama K, Kuramochi A, et al. Hemodynamic assessment of the left gastric vein in patients with esophageal varices with color Doppler EUS: Factors affecting development of esophageal varices. Gastrointest Endosc 2002;55:512-7.

38. Kuramochi A, Imazu H, Kakutani H, Uchiyama Y, Hino S, Urashima M. Color Doppler endoscopic ultrasonography in identifying groups at a high-risk of recurrence of esophageal varices after endoscopic treatment. J Gastroenterol 2007;42:219-24.

39. Romero-Castro R, Pellicer-Bautista FJ, Jimenez-Saenz M, Marcos-Sanchez F, Caunedo-Alvarez A, Ortiz-Moyano C, et al. EUS-guided injection of cyanoacrylate in perforating feeding veins in gastric varices: Results in 5 cases. Gastrointest Endosc 2007;66:402-7.

40. Binmoeller KF, Weilert F, Shah JN, Kim J. EUS-guided transesophageal treatment of gastric fundal varices with combined coiling and cyanoacrylate glue injection (with videos). Gastrointest Endosc 2011;74:1019-25.

41. Romero-Castro R, Ellrichmann M, Ortiz-Moyano C, Subtil-Inigo JC, Junquera-Florez F, Gornals JB, et al. EUS-guided coil versus cyanoacrylate therapy for the treatment of gastric varices: A multicenter study (with videos). Gastrointest Endosc 2013;78:711-21.

42. Nihoul-Fékété C, De Backer A, Lortat-Jacob S, Pellerin D. Congenital esophageal stenosis. A review of 20 cases. Pediatr Surg Int 1987;2:86-92.

43. Takamizawa S, Tsugawa C, Mouri N, Satoh S, Kanegawa K, Nishijima E, et al. Congenital esophageal stenosis: Therapeutic strategy based on etiology. J Pediatr Surg 2002;37:197-201.

44. Michaud L, Coutenier F, Podevin G, Bonnard A, Becmeur F, Khen-Dunlop N, et al. Characteristics and management of congenital esophageal stenosis: Findings from a multicenter study. Orphanet J Rare Dis 2013;8:186.

45. Romeo E, Foschia F, de Angelis P, Caldaro T, Federici di Abriola G, Gambitta R, et al. Endoscopic management of congenital esophageal stenosis. J Pediatr Surg 2011;46:838-41.

46. Terui K, Saito T, Mitsunaga T, Nakata M, Yoshida H. Endoscopic management for congenital esophageal stenosis: A systematic review. World J Gastrointest Endosc 2015;7:183-91.

47. Wildi SM, Hoda RS, Fickling W, Schmulewitz N, Varadarajulu S, Roberts SS, et al. Diagnosis of benign cysts of the mediastinum: The role and risks of EUS and FNA. Gastrointest Endosc 2003;58:362-8.

48. Faigel DO, Burke A, Ginsberg GG, Stotland BR, Kadish SL, Kochman ML. The role of endoscopic ultrasound in the evaluation and management of foregut duplications. Gastrointest Endosc 1997;45:99-103.

49. Eloubeidi MA, Cohn M, Cerfolio RJ, Chhieng DC, Jhala N, Jhala D, et al. Endoscopic ultrasound-guided fine-needle aspiration in the diagnosis of foregut duplication cysts: the value of demonstrating detached ciliary tufts in cyst fluid. Cancer 2004;102:253-8.

50. Romeo E, Torroni F, Foschia F, De Angelis P, Caldaro T, Santi MR, et al. Surgery or endoscopy to treat duodenal duplications in children. J Pediatr Surg 2011;46:874-8.

51. Riyaz A, Cohen H. Ectopic pancreas presenting as a submucosal gastric antral tumor that was cystic on EUS. Gastrointest Endosc 2001;53:675-7.

52. De Angelis P, Trecca A, Francalanci P, Torroni F, Federici Di Abriola G, Papadatou B, et al. Heterotopic gastric mucosa of the rectum. Endoscopy 2004;36:927. 
53. Fox VL, Nurko S, Teitelbaum JE, Badizadegan K, Furuta GT. High-resolution EUS in children with eosinophilic "allergic" esophagitis. Gastrointest Endosc 2003;57:30-6.

54. Dalby K, Nielsen RG, Kruse-Andersen S, Fenger C, Durup J, Husby S. Gastroesophageal reflux disease and eosinophilic esophagitis in infants and children. A study of esophageal $\mathrm{pH}$, multiple intraluminal impedance and endoscopic ultrasound. Scand J Gastroenterol 2010;45:1029-35.

55. Kouchi K, Yoshida H, Matsunaga T, Ohtsuka Y, Nagatake E, Satoh Y, et al. Endosonographic evaluation in two children with esophageal stenosis. J Pediatr Surg 2002;37:934-6.

56. Van Dam J. Endosonographic evaluation of the patient with achalasia. Endoscopy 1998;30 Suppl 1:A48-50.

57. Ellrichmann M, Wietzke-Braun P, Dhar S, Nikolaus S, Arlt A, Bethge J, et al. Endoscopic ultrasound of the colon for the differentiation of Crohn's disease and ulcerative colitis in comparison with healthy controls. Aliment Pharmacol Ther 2014;39:823-33.

58. Higaki S, Nohara H, Saitoh Y, Akazawa A, Yanai H, Yoshida T, et al. Increased rectal wall thickness may predict relapse in ulcerative colitis: A pilot follow-up study by ultrasonographic colonoscopy. Endoscopy 2002;34:212-9.

59. Lew RJ, Ginsberg GG. The role of endoscopic ultrasound in inflammatory bowel disease. Gastrointest Endosc Clin N Am 2002;12:561-71.

60. Rosen MJ, Moulton DE, Koyama T, Morgan WM $3^{\text {rd }}$, Morrow SE, Herline AJ, et al. Endoscopic ultrasound to guide the combined medical and surgical management of pediatric perianal Crohn's disease. Inflamm Bowel Dis 2010;16:461-8. 